\title{
Analysis and Research on the Teaching Principle of Automotive Engine Based on CDIO Concept
}

\author{
Huali Guo a , Jia Cui, Guofu Wang, Hongwang Zhao \\ Guilin University of Aerospace Technology, Guilin 541004, China. \\ a804017601@qq.com
}

\begin{abstract}
Keywords: CDIO Concept, Principle Automotive Engine, Teaching Reform, Teaching Content, Teaching Quality.
\end{abstract}

\begin{abstract}
The CDIO Engineering Education Philosophy pay more attention to the integration of traditional knowledge, focuses on competence development, allows students to learn engineering theory and practice in a proactive manner. Based on the CDIO concept, this article analyzes and studies the teaching reform of the "Principle of Automotive Engine" course, and proposes the teaching reforms of the core content of the course and the course teaching model. Through the reintegration of the teaching content and teaching mode, we can reach the goal of teaching quality with the clear of teaching content and objectives will be improved.
\end{abstract}

\section{Introduction}

With the continuous increase in the sales and retention of automobiles in China, the demand for automotive technology and the capabilities of maintenance and application is continuously increasing [1]. The "Principle of Automotive Engine" course is the core curriculum of the Vehicle Engineering and Automotive Service Engineering, which requires students to have the basic ability of modern automobile detection and maintenance. Based on the CDIO concept, this article analyzes and studies the teaching reform of the "Automotive Engine Theory" course, and proposes the teaching reforms of the core content of the course and the course teaching model. Through the reintegration of the teaching content and teaching mode, we can reach the goal of teaching quality with the clear of teaching content and objectives will be improved.

\section{CDIO Concept and Characteristics and Status of Course}

\subsection{CDIO Engineering Education Concept.}

The CDIO education concept is the latest and most outstanding result of the International Engineering Education Reform in recent years. CDIO stands for Conceive, Design, Implementation and Operate [2]. It takes the life cycle of product development and product operation as the carrier. It allows students to learning engineering theory and practice with the method of active attitude, practice mode and organic links between courses. Ways to learn engineering theory and practice. The CDIO Concept systematically proposes 12 standards with operative ability training, full implementation, and test evaluation. Students trained under this model are favored by companies. The advanced feasibility of CDIO concept is also suitable for the process of engineering education.

\subsection{Features and Status of the Course.}

First of all, the "Principle of Automotive Engines" is based on several basic courses. It is a theoretically strong core curriculum. Its characteristics are basic concepts, formula curves, performance indicators, and influencing factors, which are cumbersome and affect each other. It also is easy for students to feel that they are similar to the status of "fascinating arrays".[3] If they are not properly connected to each other, it will easily lead to the phenomenon that the progress of one-way infusion teaching is that teachers teach using PPT, but students learn like watching movies. Secondly, the corresponding practical verification of the course is quite weak, and it is out of touch with the theoretical teaching, which cannot achieve the seamless connection for students between learning and 
practicing. At the same time, the existing textbooks have a certain lag in the content and actual application of the new engine technology, and some of the knowledge points are too old or even eliminated in the actual application of the automobile. Finally, due to the dual impact of market economy and employment pressures, students are busy with various innovative and entrepreneurial projects, but ignore the acquisition of theoretical knowledge. They often carry the examination review method like "without review after course, assaulting before examination", which results in a lack of professional knowledge.

\section{Existing Problems in the Process of Teaching}

\subsection{Teaching Content are Relatively Backward.}

In recent years, with the increasing demand for saving energy and emission reduction in our society, modern engine technology is also developing at a rapid rate. The existing teaching materials lag behind these technological developments [4]. The new technical contents less involved in textbook, such as Variable Valve Lift and Timing, Compound Turbo-charging, Direct Injection and so on, which seriously affected the students' enthusiasm for learning, and also bring inconvenience to their future work. In order to improve the teaching effect and cultivate talents that can meet the needs of the society, the teaching contents must be updated in a timely manner.

\subsection{Insufficient Teaching Methods and Lack of Motivation.}

At present, the teaching of this course is mainly based on the way of writing on the books and PPT. There is a lack of interaction between teachers and students. Students are in a passive learning position and their enthusiasm is not high. The relatively single teaching method, on the one hand, affects the students' acceptance of professional knowledge; on the other hand, it also affects the cultivation of students' creative thinking. Although animation videos which embedded in Ventilation, Booster, Ignition, Fuel Injection.etc processes into PPT can increase students' understanding of the engine work process to a certain extent, but for this course, more emphasis is placed on the students to learn how to optimize the performance of the engine parameters by adjusting the parameters, so it is necessary to use a variety of flexible means to assisted teaching.

\subsection{Disjoint between Theoretical Teaching and Practical Teaching.}

The "Principle of Automotive Engine" course is a more practical curriculum, which has reach to achieve the purpose of combining theoretical teaching with practical teaching.[5] Due to the limitation of experimental equipment and teaching resources, the current curriculum often uses traditional teaching models (first theoretical teaching and then practical teaching). Through that way, teachers in the theory teaching only pay attention to the explanation of theoretical knowledge. In experimental teaching, the teacher only pays attention to the training in experimental operation. There is no organic combination with each other, resulting in a disconnect phenomenon between theory and practice, which seriously affects the efficiency and effectiveness of teaching and is also not conducive to cultivating students' ability to combine knowledge and skills.

\section{Analysis and Method of Teaching Reform}

\subsection{Reform and Analysis of Teaching Content.}

Under the current situation, the professional class hours of colleges and universities are continuously shrinking [4]. In order to achieve a good teaching effect, we must do the rational selection of the teaching content to simplify, which base on the concept of CDIO and around the main line of the course, to achieve the purpose of selection and optimization of content. For example, we can take this method to simplify the repetition of the electronically controlled fuel injection of gasoline engines and diesel engines, pay more attention on the control of fuel injection quantity and injection timing control, supplement plenty of latest technology, such as Direct Injection Technology, Variable Valve Timing and Lift Technology through comparing different companies, and Variable Intake Pipe Length Technology. 


\subsection{Reform and Analysis of Teaching Mode.}

According to the degree of importance of each chapter and the degree of difficulty, we can take a variety of teaching modes flexibly. We take "teaching" as the center for chapters that are important and relatively difficult to teach, and slow down the pace of teach lecture, and help students absorb and digest quickly and easily. For teaching content that is important and relatively simple, the teaching model of "teacher-oriented and student-centered" is adopted. For this part about the performance of engine, we can create a teaching method by using theory with practice as entirety and transfer the class location to the Performance Lab of the Engine. We combine the experimental teaching with multimedia teaching in the classroom. Finally, combining the characteristics of the curriculum, we can adopt a combination of "N+2" multi-mode assessment to improve the course assessment method. We can take this course distribution method as example, specifically, $10 \%$ for usual results, $15 \%$ for experimental results, $10 \%$ for mid-term results, $15 \%$ for assignments, and $50 \%$ for final grades. Ultimately, it can be easily to achieve the goals that course assessment takes a variety of ways and full-cycle approach, diversify and complete assessment methods, ensure the objectivity and comprehensiveness of the results, and to some extent improve the enthusiasm and initiative of student learning, to ensure the objectivity and comprehensiveness of the results. We can draw a conclusion that through the way as mentioned above, we can improve the enthusiasm and initiative of students' learning to some extent.

\section{Conclusion}

Combining the concept of CDIO engineering education, the integration and reform of the teaching content and teaching methods of the classic curriculum can make the teaching content and teaching objectives more clear. The students have clearer ideas for curriculum learning, the enthusiasm for learning is improved, and the ability of students in learning knowledge and analyzing capability, the use of knowledge engineering capabilities is promoted. It also provides a reference for cultivating engineering and technological talents with innovation, entrepreneurship, and cross-border integration.

\section{Acknowledgments}

The thesis is carried out with the support of the project School-level Key Course of Guilin University of Aerospace Technology-“Principle of Automotive Engine” in 2018, and Undergraduate Teaching Reform Project of Guangxi Higher Education_—Research and Practice of Project-Driven Teaching Based on CDIO in Innovative Entrepreneurial Education for Applied Undergraduate Engineering Talents in 2017(2017JGB428). "The construction and practice of the curriculum system of automobile inspection and maintenance specialty based on the cultivation of post professional ability” (NO.GXGZJG2016A058).

\section{References}

[1]. Yan Zheng, Dan Zhang, Wei Cui etc. Discussion on teaching method of engine principle course [J]. Journal of Jiangsu University of Science and Technology, 2016, 22 (04):119-121.

[2]. Bauhaus $\mathrm{Wu}$, Hue Zhang. Introduction to the Internalization Path of the Idea of CDIO Engineering Education [J].Heilongjiang Education (Higher Education Research and Evaluation), 2016 (05): 61-62.

[3]. Jinxing Hour, Zhen Hua Wen. Research and Practice of Automobile Specialty Course Teaching Based on Simulation Technology [J]. New Course Research, 2015(7):17-18.

[4]. Jian Huang, Ying Shen, Hogweed Wang. The Practice and Research of the Teaching Reform of "Principle of Automotive Engine "[J]. Education and Teaching Forum, 2017 (04):171-172. 
[5]. Saying Yang, Yu Chen. Exploration and Practice of the Teaching Content Reform of "Principle of Automotive Engine" Course Based on CDIO Engineering Education Concept [J]. Science \& Technology Market, 2017 (09):160-161. 